\title{
Virus like particle-based vaccines against emerging infectious disease viruses
}

\author{
Jinliang Liu, Shiyu Dai, Manli Wang, Zhihong Hu, Hualin Wang, Fei Deng
}

State Key Laboratory of Virology, Wuhan Institute of Virology, Chinese Academy of Sciences, Wuhan 430071, China

Emerging infectious diseases are major threats to human health. Most severe viral disease outbreaks occur in developing regions where health conditions are poor. With increased international travel and business, the possibility of eventually transmitting infectious viruses between different countries is increasing. The most effective approach in preventing viral diseases is vaccination. However, vaccines are not currently available for numerous viral diseases. Viruslike particles (VLPs) are engineered vaccine candidates that have been studied for decades. VLPs are constructed by viral protein expression in various expression systems that promote the selfassembly of proteins into structures resembling virus particles. VLPs have antigenicity similar to that of the native virus, but are non-infectious as they lack key viral genetic material. VLP vaccines have attracted considerable research interest because they offer several advantages over traditional vaccines. Studies have shown that VLP vaccines can stimulate both humoral and cellular immune responses, which may offer effective antiviral protection. Here we review recent developments with VLP-based vaccines for several highly virulent emerging or re-emerging infectious diseases. The infectious agents discussed include RNA viruses from different virus families, such as the Arenaviridae, Bunyaviridae, Caliciviridae, Coronaviridae, Filoviridae, Flaviviridae, Orthomyxoviridae, Paramyxoviridae, and Togaviridae families.

\section{KEYWORDS emerging infectious disease; self-assembly; vaccine; virus; virus-like particle (VLP)}

\section{INTRODUCTION}

With the increase in international travel, pathogen transmission across countries has increased and has resulted in several pandemics, especially of viral diseases. In 2012, the outbreak of a newly identified coronavirus, Middle East respiratory syndrome coronavirus (MERS-CoV) was reported in Saudi Arabia (de groot et al., 2013). As of December 2015, the World Health Organization (WHO) was notified of 1625 laboratory-confirmed MERS-CoV infections from 26 countries, with at least 586 deaths (WHO, 2016). In March 2014, an Ebola virus disease out-

Received: 29 February 2016, Accepted: 25 June 2016,

Published online: 11 July 2016

$\triangle$ Correspondence:

Phone: +86-27-87198465, Fax: +86-27-87198465

Email: df@wh.iov.cn

ORCID: 0000-0002-5385-083X break was reported in West Africa. By December 2015, 28, 637 cases of Ebola infection were reported, including 11,315 deaths (WHO, 2015), with mortality rates of up to $40 \%$. Such pandemics cause significant mortality and economic losses; thus, it is critical to prevent the spread of emerging viruses.

Vaccination is most effective in preventing viral infection; however, vaccine development against emerging viruses faces several challenges. Some emerging viruses cause high infectivity and mortality; therefore, a maximum (level 4) biosafety lab is needed, and live attenuated strains or inactivated vaccines are not adequately safe (Garcia-sastre and Mena, 2013). Second, in an outbreak of infections by an emerging virus, every second matters; therefore, a rapid development of engineered vaccines is required for pandemic control. Third, some vaccines, such as influenza virus vaccines, are not effective against all strains. Because of mutations, antigenic drift, and antigenic 
shift, influenza virus strains differ with influenza seasons and pandemics. Furthermore, because a virus cannot reproduce autonomously in vitro, vaccines against viruses are produced by propagating viruses in large quantities in living cells of susceptible organisms. For example, traditional influenza vaccines are manufactured using embryonated chicken eggs for virus propagation. However, some viruses still cannot be cultured in cells or organs, outside of the natural host(s).

Virus-like particles (VLPs) are generated from viral proteins that self-assemble into structures resembling native virions and can have some antigenicity of the native virus, but are non-infectious due to their lack of viral genetic material. VLPs have been studied as vaccines for decades, and the first VLP-based vaccine approved by the US FDA was the HBV vaccine (HEPTAVAX-B; Merck; 1981) (Zhao et al., 2013). More recently, 2 VLP-based HPV vaccines, Gardasill (Merck and Co. Inc.) and Cervarix 1 (GlaxoSmithKline), were approved by the US FDA. These vaccines are produced in yeast and insect cells, respectively (Rodriguez-limas et al., 2013). With advances in biotechnology, the development of VLP vaccines has progressed greatly. VLPs offer several advantages as vaccines against emerging viruses. First, safety consideration in developing these vaccines is not necessary, as VLPs are not live viruses; thus, the manufacturing process offers a safer environment for the operators. Second, VLPs can display major antigens and elicit strong humoral and cellular immune responses. The potency of VLPs in stimulating immune responses can be significantly enhanced relative to inactivated viral particles, as viruses have evolved different ways to evade the host immune system. Some structural and non-structural proteins inhibit immune responses, especially cellular immune responses (Frazer et al., 1999; Pukhalsky et al., 2003; Sarobe et al., 2003), but VLPs can be deficient in proteins or domains that inhibit immune responses. Compare to the individual proteins or peptides, VLPs have better immunogenicity, as the peptides conformation of VLPs is more similar to the virus than in inactivated viruses. Due to highly repetitive epitopes on the surface, VLPs are able to induce strong B cells responses (Roldão et al., 2010). VLPs can also be internalized by antigen presenting cells that active $\mathrm{CD} 4^{+}$and $\mathrm{CD} 8^{+} \mathrm{T}$ cells to elicit and sustain specific cytotoxic $\mathrm{T}$ lymphocyte (CTL) responses (Wagner et al., 1994; Chackerian et al., 2002; Cox et al., 2014), and $\mathrm{CD} 4{ }^{+} \mathrm{T}$ cells play an important role in sustaining virusspecific $\mathrm{CD} 8^{+}$CTLs during virus infection (Matloubian et al., 1994).

Several platforms for producing VLPs exist, such as bacteria (Escherichia coli), yeast, insect cells, mammalian cells, plant expression systems, and in vitro cell-free systems. The bacterial expression system was the first system used to produce VLPs, and several commercial VLP vaccines have been produced using this system, such as one against hepatitis E virus (HEV) VLPs (Hecolin1, Xiamen Innovax Biotech Co. Ltd.). The E. coli expression system is the most economical and easy-to-use system. However, this system lacks a post-translational modification system and can only be used to produce simple VLPs, such as non-enveloped VLPs, which are based on the ability of viral protein components to self-assemble in the bacterial host during expression. Yeast systems are commonly used in VLP vaccine production, for example with the HBV vaccine Engerix- ${ }^{\mathbb{B}}$ (GlaxoSmithKline) and the HPV vaccine Gardasil ${ }^{\circledR}$ (Merck \& Co., Inc). Yeast systems offer high expression and easy scale-up and, unlike the $E$. coli system, provide post-translational modification of the expressed proteins. However, neither the E. coli nor the yeast system can express enveloped VLPs. The baculovirus-insect cell and mammalian-cell systems show more complete post-translational modification including glycosylation and are better systems for expressing complex VLPs (Rodriguez-limas et al., 2013). Successful VLP vaccines produced using these systems include the HPV vaccine Cervix ${ }^{\circledR}$ (GlaxoSmithKline) and the HBV vaccine GenHevac B ${ }^{\circledR}$ (Pasteur-Mérieux Aventis). These systems are more expensive than E. coli and yeast, and downstream processing is more difficult. In the plant expression system, protein assembly and post-translational modifications are similar to those occurring in mammalian cells. As production system, it is cost-effective and highly scalable.

Most emerging human pathogens are single-stranded RNA viruses. Here, we summarize several VLP vaccines against emerging viruses, including negative-strand RNA viruses belonging to 5 families (Arenaviridae, Bunyaviridae, Filoviridae, Orthomyxoviridae and Paramyxoviridae) and positive-strand RNA viruses from 4 families (Caliciviridae, Coronaviridae, Flaviviridae, and Togaviridae). Some viruses from these families are human pathogens with high virulence and lethality, and vaccines against these viruses are urgently needed for pandemic control.

\section{NEGATIVE-STRAND RNA VIRUSES}

\section{Arenaviridae family}

Arenaviruses are pathogens of rodents-transmitted diseases, some of which cause severe cases and are responsible for hemorrhagic fever (Oldstone, 2002). Lassa fever is an acute viral illness that has been reported in West Africa and is caused by Lassa fever virus (LASV), which is a member of the Arenaviridae family. The genome of LASV consists of 2 RNA segments ( $\mathrm{S}$ and L). The S segment encodes the viral nucleocapsid protein (NP) and 2 glycoproteins (GP1 and GP2), whereas the L segment encodes the viral polymerase (L) and RING-finger matrix 
protein $(\mathrm{Z})$. GP1 and GP2 are generated from post-translational cleavage of a precursor glycoprotein (GPC). GP1 serves as receptor-binding protein, while GP2 is a transmembrane protein (Oldstone, 2002). The $\mathrm{Z}$ protein is considered the main driving force of virus release. The $\mathrm{Z}$ protein is sufficient for the release of viral particles, and it is strongly membrane-associated. Previous findings show that expression of the $\mathrm{Z}$ protein alone is sufficient for the release of lipid-enveloped VLPs (Strecker et al., 2003).

LASV VLPs have been generated using a mammalian cell expression system by expressing the major immunological determinants: glycoproteins (GP1 and GP2), NP, and $Z$. The viral proteins can be packaged into particles similar to the native virion. LASV VLP-immunized mice mounted a substantially high IgG re-sponse to individual viral proteins, and the serum from LASV-infected patients reacted to the VLPs (Branco et al., 2010).

\section{Bunyaviridae family}

The Bunyaviridae family contains 5 genera, namely $\mathrm{Or}$ thobunyavirus, Phlebovirus, Nairovirus, Hantavirus, and Tospovirus. Tospoviruses are plant-infecting viruses, while viruses of the other 4 genera infect animals. Most viruses in this family are transmitted and carried by arthropods, while hantaviruses are rodent-borne. The genome of Bunyaviridae contains 3 negative-sense RNA segments: the large segment (L), middle segment (M), and small segment (S). Bunyaviridae virions are $80-120 \mathrm{~nm}$ in diameter and mostly spherical. Glycoprotein spikes are displayed on the surface, which mostly consist of 2 heterodimeric GPs, which are embedded into the viral envelop. The GPs (Gn and Gc) interact to form surface morphologic units. The virions mature and bud from the Golgi complexes of infected cells (Li et al., 2010).

Some VLP vaccines have been developed for members of the Bunyaviridae family. Hantavirus-like particles can be obtained by co-expressing $\mathrm{Gn}, \mathrm{Gc}$, and NP in $\mathrm{CHO}$ cells. The viral proteins self-assemble into VLPs, and animal experiments showed that the Hantavirus VLPs elicit comparable antibody responses to inactivated vaccines and enhance the activity of $\mathrm{CD}^{+}{ }^{+} \mathrm{T}$ cells (Li et al., 2010). However, not all 3 proteins are necessary for VLP formation. Rodrigo Acuna et al. showed that Gn and Gc co-expressed $\mathrm{Gn}$ and $\mathrm{Gc}$ in mammalian cells assemble into VLPs, suggesting that the NP protein is not necessary for VLP assembly (Acuna et al., 2014). VLPs with other members of the Bunyaviridae family can also form after Gn and Gc co-expression (Overby et al., 2006; Mandell et al., 2010).

Two other human pathogens, Crimean-Congo hemorrhagic fever virus (CCHFV) and severe fever with thrombocytopenia-syndrome virus (SFTSV), are serious health threats with no available vaccine or specific therapeutic method. Zhou et al. reported that expression of the NP of
CCHFV using a baculovirus expression system yields VLPs (Zhou et al., 2011). However, the immunogenicity and protective efficacy of such VLPs have not been reported. Although no CCHFV and SFTSV VLP vaccines have been reported, studies of viruses from the same family indicate that the expression of these 2 viral proteins can yield VLPs. This new strategy could be used to develop vaccines against CCHFV and SFTSV.

\section{Filoviridae family}

Filoviruses are enveloped, non-segmented, negative-strand RNA viruses. This family has 2 genera, Ebolavirus and Marburgvirus. Filoviruses are notable for their high mortalities in humans, and no effective vaccines or treatments are available. The matrix protein VP40 is the major structural protein, and previous data show that VP40 contains the necessary information for the assembly and budding of filovirus VLPs, although solely expressing VP40 results in poor VLP production (Warfield and aman, 2011).

Ebola viruses contain 5 species, Bundibugyo ebolavirus (BDBV), Zaire ebolavirus (EBOV), Reston ebolavirus (RESTV), Sudan ebolavirus (SUDV), and Taï Forest ebolavirus (TAFV) (Singh et al., 2015). BDBV, EBOV, and RESTV have caused pandemics in Africa. RESTV infection has been found in Asia, but no pathogenic or lethal cases have been reported. EBOV was the etiological agent of the 2014 Ebola outbreak in West Africa (Baize et al., 2014). The EBOV VLP vaccine has been studied for several years. Warfield et al. co-transfected Ebola VP40 and glycoprotein (GP) into $293 \mathrm{~T}$ cells, and the viral proteins self-assembled into particles with morphologies similar to that of the wild-type virus. The EBOV VLPs were highly immunogenic in vitro and in vivo. EBOV VLPs efficiently induced the maturation, activation, and secretion of cytokines and chemokines. EBOV VLP-vaccinated mice exhibited $B$ cell activation and produced high levels of EBOV-specific antibodies. The VLPs also activated $\mathrm{CD}^{+}$and $\mathrm{CD}^{+} \mathrm{T}$ cells. The EBOV VLPs could also protect the mice from lethal challenge (Warfield et al., 2003). EBOV VLPs were also produced in insect cells by expressing VP40 and GP in a baculovirus expression system, and the resulting VLPs also effectively protected the mice from lethal EBOV challenge (Warfield et al., 2007). EBOV VLP production in insect cells had a high yield, and the VLPs showed potential to for development into an effective EBOV vaccine.

The Marburgvirus genus has only 1 species, Lake Victoria Marburg virus. A single protein, VP40, can generate VLPs of the virus, but the efficiency of VLP generation is lower than that following co-expression with other proteins, especially GP, NP, and VP24, which can significantly promote the formation and budding of the virions (Warfield and aman, 2011). Previous data showed that co-expression of VP40 and GP (with or without NP) in 
mammalian and insect cells yielded similar particles with morphologies similar to that of the native virion (Swenson et al., 2004; Warfield et al., 2007). Guinea pigs vaccinated with Marburg VLPs produced in mammalian cells elicited abundant MARV-specific antibodies and neutralizing antibodies. MARV VLPs stimulated dendritic cell differentiation, promoted T-cell proliferation, and completely protected guinea pigs from MARV infection (Warfield and aman, 2011). The VLPs not only protected rodents from virus infection, but also protected non-human primates (NHPs). The level of MARV-specific antibodies in VLP-vaccinated monkeys increased quickly after the first vaccination, and peaked after the third vaccination (Warfield and aman, 2011).

\section{Orthomyxoviridae family}

High pathogenic avian influenza (HPAI) is a highly contagious and highly lethal infectious disease that circulates in birds and poultries. HPAI is mainly caused by $\mathrm{H} 5$ or $\mathrm{H} 7$ influenza A virus (Swayne and Suarez, 2000). Influenza A virus belongs to the Orthomyxoviridae family. Viruses of the Orthomyxoviridae family have negative-sense, singlestranded, and segmented RNA genomes. There are 6 genera in this family, including influenza A, B, C; Thogotovirus; Isavirus, and a new genus Quar-anilvirus (L'vov et al., 2014). Influenza virus is enveloped with a lipid membrane derived from the host membrane. Hemagglutinin (HA) and neuraminidase (NA) are the major surface glycoproteins in the viral membrane and represent the main epitopes. The matrix gene encodes two proteins, the M1 protein, which is involved in viral budding, and the M2 protein, which is a transmembrane, homotetrameric proton ion channel involved in virus uncoating following entry. The M2 protein has been the target of universal vaccine design, as the external region is highly conserved in human influenza viruses.

The traditional influenza vaccine is an egg-based inactive vaccine, but this strategy has limited applications as the HPAI virus is lethal to chick embryos. A VLP-based vaccine is a novel approach for treating HPAI. Many studies have been conducted on the development of influenza VLP vaccines (Kang et al., 2009), although no vaccine is currently available. Influenza VLPs were constructed by co-expressing HA or/and NA with the M1 and M2 proteins (Buonaguro et al., 2011). HPAI VLPs have been generated in insect cells (Bright et al., 2008), mammalian cells (Schmeisser et al., 2012), and plants (Landry et al., 2010). An H5 VLP produced in plants, which can protect ferrets from lethal challenge, has been described. Data from a Phase I clinical study showed that the plant-produced $\mathrm{H} 5$ vaccine was safe. After 2 vaccinations, $100 \%$ of ferrets had detectable HI antibodies. The H5 VLP vaccine also induced detectable cross-reactive $\mathrm{HI}$ antibodies in ferrets. The clinical study provided evidence that the VLP was well tolerated in humans, and HI titers rose to $\geq 40$ in $16.7 \%, 25 \%$, and $50 \%$ of the subjects after the second dose in the 5, 10, and $20 \mathrm{mg}$ groups, respectively. No HI antibodies were detected in the sera from subjects of the placebo group (Landry et al., 2010). H5 VLPs containing HA, NA, and M1 expressed in insect cells by the baculovirus expression system could also protect mice from lethal challenge and offered cross protection against a heterogeneous H5N1 virus (Bright et al., 2008). Several companies, including Novavax (MD, USA), have developed an H5N1 VLP vaccine produced by insect cells, which are under Phase I clinical study.

\section{Paramyxoviridae family}

Nipah virus (NiV) and Hendra virus $(\mathrm{HeV})$ belong to the Paramyxoviridae family. They are enveloped RNA viruses consisting of a membrane derived from host cells, a matrix protein $(\mathrm{M})$, and 2 glycoproteins (F and $\mathrm{G}$ ) embedded in the membrane. The paramyxovirus matrix protein localizes to the cellular membrane after expression in an infected cell and then recruits the glycoproteins to the membrane. The glycoproteins then assemble and bud from the membrane. The matrix protein was reported as the main driving force for particle budding and scission (Harrison et al., 2010).

Paramyxovirus VLPs can assemble following co-expression of viral matrix protein and glycoproteins. NiV VLPs can be produced in $293 \mathrm{~T}$ cell lines by co-transfection of plasmids encoding the NiV G, F, and M proteins (Walpita et al., 2011). Newcastle disease virus (NDV) has been used as a vector to express NiV proteins in BHK-21 cells. Animal tests showed that NiP VLP-vaccinated mice produced abundant $\mathrm{NiV}$-specific antibodies and mounted a strong, active $\mathrm{CD} 8^{+} \mathrm{T}$ cell reaction. Neutralizing antibodies were also detected in NiP VLP-vaccinated pigs, but $\mathrm{CD}^{+} \mathrm{T}$ cells were not detected (Kong et al., 2012).

VLPs of other Paramyxoviridae viruses, such as respiratory syncytial virus (RSV), have been constructed, and pre-clinical study results are promising (Mcginnes et al., 2011). No studies have been reported for Hendra viruslike particles, but as a paramyxovirus, we speculate that $\mathrm{HeV}$ VLP can be similarly produced.

\section{POSITIVE-STRAND RNA VIRUSES}

\section{Caliciviridae family}

Norovirus (NoV), the most common causative agent of non-bacterial gastroenteritis in humans, is a member of the Norovirus genus of the Caliciviridae family (Patel et al., 2009). NoV affects people of all ages and is responsible for more than $95 \%$ of epidemic viral gastroenteritis in adults. NoV has a single-stranded, positive-sense RNA genome that encodes a major structural protein (VP1) and 
a minor capsid protein (VP2). The viral particles demonstrate an amorphous surface structure between 27 and 28 $\mathrm{nm}$ in size. The Norovirus genus is divided into 6 genogroups (GI-GVI), which are further divided into different genotypes based on greater than $15 \%$ pairwise differences in the amino acid sequence of the VP1 capsid proteins (Ramani et al., 2014). Viruses in geno-groups I , II, and IV are known to infect humans, and NoVs of genogroup II and genotype IV (G II .4) are currently circulating widely (Herbst-kralovetz et al., 2010).

The lack of an in vitro cultivation method limits the development of traditional vaccines (Moore et al., 2015), which makes VLPs very attractive candidates for vaccines. The results of several studies have demonstrated the immunogenicity and safety of NoV VLPs delivered by oral and intranasal routes. Expression of recombinant $\mathrm{NoV}$ capsid proteins in insects, plants (Scotti and Rybicki, 2013), and mammalian cells (Harrington et al., 2002) has yielded VLPs that are morphologically and antigenically similar to the native virion. Preclinical mouse data showed that VLPs can induce humoral and mucosal immunity when delivered through oral, intranasal, or parenteral routes. In a Phase I clinical study, Ball et al. assessed the safety and immunogenicity of VLPs delivered orally (Ball et al., 1996). In a subsequent study, the efficacy of intranasally administered VLPs was evaluated. A drypowder formulation of baculovirus-derived VLPs adjuvanted with monophosphoryl lipid A and the mucoadherent chitosan was tested. It was well tolerated with no severe adverse effects and showed a dose-dependent increase in serum antibody titers (El-kamary et al., 2010). Data from studies on bivalent and multivalent VLP candidate vaccines in adult volunteers showed that multivalent VLP vaccines induced a broad antibody response to multiple epitopes of vaccine and non-vaccine NoV strains (Lindesmith et al., 2015). VLPs have also been developed as promising candidate vaccines against NoV infection and have shown efficacy in a proof-of-concept human experimental infection model (Atmar et al., 2011).

\section{Coronaviridae family}

Coronaviruses are enveloped RNA viruses, that cause acute or persistent infectious in humans and other animals. Human severe acute respiratory syndrome coronavirus (SARS-CoV) and MERS-CoV are 2 major human coronaviruses cause severe human illness. SARS-CoV was identified in an outbreak occurring in 2003, in China. Recently, MERS emerged as an infectious disease, first reported in Saudi Arabia in 2012 and causing a subsequent outbreak in South Korea. The illness is caused by MERS-CoV, which is a member of the Betacoronavirus genus of the Coronaviridae family. Virions of the coronavirus are roughly spherical, the average diameters of which range from 50 to $200 \mathrm{~nm}$. CoV particles comprise 4 structural proteins: the spike protein (S), envelope protein $(\mathrm{E})$, membrane protein $(\mathrm{M})$, and nucleocapsid protein $(\mathrm{N})$.

Experiments on SARS VLPs showed that expression of SARS-CoV viral proteins $M$ and $E$ in baculovirus leads to the formation of a smooth particle without spikes, whereas co-expression of M, E, and S yields SARS VLPs (Mortola and Roy, 2004). Lu et al. found that mucosal or systemic immunization with SARS VLPs produced using the baculovirus expression system resulted in a strong $\mathrm{IgG}$ and secreted IgA response. SARS VLPs can also activate DCs and elicit cellular immune responses (Bai et al., 2008; Lu et al., 2010).

\section{Flaviviridae family}

Flaviviridae viruses are single-stranded, positive-sense RNA viruses. The virions are spherical, $40-60 \mathrm{~nm}$ in diameter, with a lipid envelope derived from the host cell membrane. The viral genome encodes 3 structural proteins: core protein $(C)$, envelope protein $(E)$, and membrane glycoprotein (M). Protein $\mathrm{E}$ is a glycoprotein that functions as a fusion protein, and it is the major target of neutralizing antibodies (Schweitzer et al., 2009). Protein $\mathrm{M}$ is translated in an immature form, PrM, and following cleavage by a cellular enzyme (furin), develops into the $\mathrm{M}$ protein in the mature virion.

Tick-borne encephalitis (TBE) is a serious viral disease caused by 2 viruses from the Flaviviridae family: central European encephalitis (CEE) virus and Russian springsummer encephalitis (RSSE) virus. An inactivated TBEvirus vaccine is currently available. A TBE-VLP vaccine is not available, but VLPs for many other flaviviruses, such as Dengue fever virus (DENV) (Zhang et al., 2011) and Japanese encephalitis virus (JEV) (Yamaji et al., 2013) exist. PrM and protein E mediate the assembly and budding of flaviviruses. A previous study has provided evidence that PrM and E self-assemble into morphologically similar particles and that protein E (without PrM) forms VLPs (Du et al., 2015).

DENV, the etiological agent of dengue has 4 sero-types (DENV 1-4). DENV VLPs have been studied in several systems (mammalian cells, Pichia pastoris, insect cells, and E. coli) by expressing the viral proteins, PrM and E (Purdy and chang, 2005; Mani et al., 2013). These studies showed evidence that DENV VLPs stimulate immunized mice to produce abundant neutralizing antibodies and elicit a strong T cell response (Zhang et al., 2011). Mani et al. reported that DENV E protein alone can form VLPs, and the resulting VLPs had good immunogenicity, eliciting a strong specific antibody response (Mani et al., 2013). DENV VLPs are also good antigens for antibody detection in patient sera (Holmes et al., 2005). 


\section{Togaviridae family}

Chikungunya fever virus (CHIKV) is an arthropod-borne virus that is transmitted to humans by mosquitoes. It causes a severe disease whose common symptoms are fever and joint pain (Staples et al., 2009). CHIKV is a member of the Alphavirus genus of the Togaviridae family. The virus particle consists of an icosahedral nucleocapsid and an envelope derived from the host cell membrane. The nucleocapsid is composed of 240 copies of coat protein $(\mathrm{C})$ and is $60-70 \mathrm{~nm}$ in diameter. The envelope contains heterodimers composed of the E1 and E2 glycoproteins. CHIKV VLPs can be produced by transfecting the viral protein genes $(C-E$ or $E)$ into HEK293 cells. The vaccine potential of the VLPs derived from transfected HEK293 cells has been demonstrated in rodents and NHPs. Immunological experiments showed that this kind of VLP elicited specific antibody and neutralizing antibody responses in immunized animals. This VLP has been approved for Phase I clinical trials (Akahata et al., 2010). Attempts to produce CHIKV VLPs using a baculovirus expression system have been reported. Specific and neutralizing antibody responses elicited by CHIKV VLPs produced using the baculovirus expression system equaled those of VLPs produced in a mammalian cell system and could completely protect guinea pigs from lethal challenge (Metz et al., 2013).

\section{CONCLUSION}

Infectious diseases are always big threats to human health. With advances in biology and medical science, efforts to understand these pathogens and prevent infections need to increase. VLPs represent a new approach for developing vaccines against viruses, although only a few have reached the market and no VLP-based vaccine against emerging viruses is currently available. The first reason for this is the lack of knowledge regarding these new emerging viruses. Secondly, a good animal model is not available for infections by these viruses to test vaccines, including common vaccines and VLPs. Third, the purification technology of VLPs is a main limitation for their being licensed as vaccines. Because VLPs are expressed using different expression systems, VLPs are often contaminated with residual host cell components such as lipids, nucleic acids, and proteins which may stimulate immune responses, resulting in a major safety concern. More efficient technologies should be explored, which may contribute to VLP production and purification, and promote the use of VLPs as novel vaccines for controlling emerging viruses.

The successes of the HBV and HPV VLP vaccines have encouraged exploration of the possibilities of developing VLP vaccines against various viruses. To date, $>100$ VLPs, representing different virus families, having been developed (Zeltins, 2013). In Table 1, we have summarized VLPs from 10 different virus families and construction of the representative VLPs. Since 2006, only the HPV VLP vaccine has been approved for sale. No VLP vaccines have been licensed thereafter, although many have been tested on animals. Researchers have great expectations for several VLP vaccines based on the positive results of clinic trials, such as with a seasonal influenza VLP (Khurana et al., 2011; López-Macías et al., 2011) and a Norwalk VLP vaccine (Herbst-Kralovetz et al., 2010). Hopefully, more VLP vaccines may be approved in the near future.

Table 1. Summary of construction strategies of VLPs from different virus families

\begin{tabular}{|c|c|c|c|c|}
\hline Family & Representative virus & Proteins & Expression system & Reference \\
\hline Arenaviridae & LASV & GPC, NP, Z & HEK-293T/17 cell & Branco et al., 2010 \\
\hline Bunyaviridae & Hantavirus & Gn, Gc, NP & $\mathrm{CHO}$ cell & Li et al., 2010 \\
\hline Caliciviridae & Norwalk virus & Major capsid protein & Insect cell & Ball et al., 1998 \\
\hline Coronaviridae & SARS coronavirus & $M, E, S$ & Insect cell & Mortola and Roy, 2004 \\
\hline Filoviridae & Ebola virus & VP40, GP, NP & 293T cell, insect cells & $\begin{array}{l}\text { Warfield et al., } 2003 \text {, } \\
\text { Warfield et al., } 2007\end{array}$ \\
\hline Flaviviridae & Dengue fever virus & PrM, E & 293T cell, P. pastoris & $\begin{array}{l}\text { Zhang et al., 2011; Liu } \\
\text { et al., } 2014\end{array}$ \\
\hline Orthomyxoviridae & Influenza virus A & $\mathrm{HA}, \mathrm{NA}, \mathrm{M} 1$ & Insect cell, plant cell & $\begin{array}{l}\text { Quan et al., 2007, } \\
\text { D'aoust et al., } 2010\end{array}$ \\
\hline Paramyxoviridae & $\begin{array}{l}\text { Human respiratory } \\
\text { syncytial virus RSV } \\
\text { Human }\end{array}$ & $\mathrm{M}, \mathrm{F}, \mathrm{G}$ & Insect cell & Quan et al., 2011 \\
\hline Retroviridae & $\begin{array}{l}\text { immunodeficiency virus } \\
\text { (HIV) }\end{array}$ & $\operatorname{Pr} 55^{\text {gag }}$, GP160, Rev & $\begin{array}{l}\text { Drosophila S2 cell, insect } \\
\text { cell }\end{array}$ & $\begin{array}{l}\text { Buonaguro et al., 2005; } \\
\text { Yang et al., } 2012\end{array}$ \\
\hline Togaviridae & $\begin{array}{l}\text { Chikungunya } \\
\text { virus(CHIKV) }\end{array}$ & C, E3, E2, 6k, E1 & 293 cell & Noranate et al., 2014 \\
\hline
\end{tabular}




\section{COMPLIANCE WITH ETHICS GUIDELINES}

The authors declare that they have no conflicts of interest. This article does not contain any studies with human or animal subjects performed by any of the authors.

\section{REFERENCES}

Acuna R, Cifuentes-Munoz N, Marquez CL, Bulling M, Klingstrom J, Mancini R, Lozach PY, Tischler ND. 2014. Hantavirus Gn and Gc glycoproteins self-assemble into virus-like particles. J Virol, 88: 2344-2348.

Akahata W, Yang ZY, Andersen H, Sun S, Holdaway HA, Kong WP, Lewis MG, Higgs S, Rossmann MG, Rao S, Nabel GJ. 2010. A virus-like particle vaccine for epidemic Chikungunya virus protects nonhuman primates against infection. Nat Med, 16: 334-338.

Atmar RL, Bernstein DI, Harro CD, Al-Ibrahim MS, Chen WH, Ferreira J, Estes MK, Graham DY, Opekun AR, Richardson C, Mendelman PM. 2011. Norovirus Vaccine against Experimental Human Norwalk Virus Illness. New Engl J Med, 365: 21782187.

Bai B, Hu Q, Hu H, Zhou P, Shi Z, Meng J, Lu B, Huang Y, Mao P, Wang H. 2008. Virus-like particles of SARS-like coronavir-us formed by membrane proteins from different origins demon-strate stimulating activity in human dendritic cells. PLoS One, 3: e2685.

Baize S, Pannetier D, Oestereich L, Rieger T, Koivogui L, Magassouba N, Soropogui B, Sow MS, Keita S, De Clerck H, Tiffany A, Dominguez G, Loua M, Traore A, Kolie M, Malano ER, Heleze E, Bocquin A, Mely S, Raoul H, Caro V, Cadar D, Gabriel M, Pahlmann M, Tappe D, Schmidt-Chanasit J, Impouma B, Diallo AK, Formenty P, Van Herp M, Gunther S. 2014. Emergence of Zaire Ebola virus disease in Guinea. N Engl J Med, 371: 1418-1425.

Ball JM, Estes MK, Hardy ME, Conner ME, Opekun AR, Graham DY. 1996. Recombinant Norwalk virus-like particles as an oral vaccine. Arch Virol, Suppl 12: 243-249.

Ball JM, Hardy ME, Atmar RL, Conner ME, Estes MK. 1998. Oral immunization with recombinant Norwalk virus-like particles induces a systemic and mucosal immune response in mice. J Virol, 72: $1345-1353$.

Branco LM, Grove JN, Geske FJ, Boisen ML, Muncy IJ, Magliato SA, Henderson LA, Schoepp RJ, Cashman KA, Hensley LE, Garry RF. 2010. Lassa virus-like particles displaying all major immunological determinants as a vaccine candidate for Lassa hemorrhagic fever. Virol J, 7: 279.

Bright RA, Carter DM, Crevar CJ, Toapanta FR, Steckbeck JD, Cole KS, Kumar NM, Pushko P, Smith G, Tumpey TM, Ross TM. 2008. Cross-clade protective immune responses to influenza viruses with $\mathrm{H} 5 \mathrm{~N} 1 \mathrm{HA}$ and NA elicited by an influenza virus-like particle. PLoS One, 3: e1501.

Buonaguro L, Tagliamonte M, Tornesello ML, Buonaguro FM. 2011. Developments in virus-like particle-based vaccines for infectious diseases and cancer. Expert Rev Vaccines, 10: 15691583.

Buonaguro L, Visciano ML, Tornesello ML, Tagliamonte M, Biryahwaho B, Buonaguro FM. 2005. Induction of systemic and mucosal cross-clade neutralizing antibodies in BALB/c mice immunized with human immunodeficiency virus type 1 clade $A$ virus -like particles administered by different routes of inoculation. J Virol, 79: 7059-7067.

Chackerian B, Lenz P, Lowy DR, Schiller JT. 2002. Determinants of autoantibody induction by conjugated papillomavirus virus-like particles. J Immunol, 169: 6120-6126.

Cox RG, Erickson JJ, Hastings AK, Becker JC, Johnson M, Craven RE, Tollefson SJ, Boyd KL, Williams JV. 2014. Human metapneumovirus virus-like particles induce protective $\mathrm{B}$ and $\mathrm{T}$ cell responses in a mouse model. J Virol, 88: 6368-6379.

D'Aoust MA, Couture MM, Charland N, Trepanier S, Landry N, Ors F, Vezina LP. 2010. The production of hemagglutinin-based virus-like particles in plants: a rapid, efficient and safe response to pandemic influenza. Plant Biotechnol J, 8: 607-619.

de Groot RJ, Baker SC, Baric RS, Brown CS, Drosten C, Enjuanes L, Fouchier RAM, Galiano M, Gorbalenya AE, Memish ZA, Perlman S, Poon LLM, Snijder EJ, Stephens GM, Woo PCY, Zaki AM, Zambon M, Ziebuhr J. 2013. Middle East Respiratory Syndrome Coronavirus (MERS-CoV): Announcement of the Coronavirus Study Group. J Virol, 87: 7790-7792.

Du R, Yin F, Wang M, Hu Z, Wang H, Deng F. 2015. Glycoprotein $E$ of the Japanese encephalitis virus forms virus-like particles and induces syncytia when expressed by a baculovirus. J Gen Virol, 96: 1006-1014.

El-Kamary SS, Pasetti MF, Mendelman PM, Frey SE, Bernstein DI, Treanor JJ, Ferreira J, Chen WH, Sublett R, Richardson C, Bargatze RF, Sztein MB, Tacket CO. 2010. Adjuvanted Intranasal Norwalk Virus-Like Particle Vaccine Elicits Antibodies and Antibody-Secreting Cells That Express Homing Receptors for Mucosal and Peripheral Lymphoid Tissues. J Infect Dis, 202: 1649-1658.

Garcia-Sastre A, Mena I. 2013. Novel vaccine strategies against emerging viruses. Curr Opin Virol, 3: 210-216.

Harrington PR, Yount B, Johnston RE, Davis N, Moe C, Baric RS. 2002. Systemic, mucosal, and heterotypic immune induction in mice inoculated with Venezuelan equine encephalitis replicons expressing Norwalk virus-like particles. J Virol, 76: 730-742.

Harrison MS, Sakaguchi T, Schmitt AP. 2010. Paramyxovirus assembly and budding: building particles that transmit infections. Int J Biochem Cell Biol, 42: 1416-1429.

Herbst-Kralovetz M, Mason HS, Chen Q. 2010. Norwalk virus-like particles as vaccines. Expert Rev Vaccines, 9: 299-307.

Holmes DA, Purdy DE, Chao DY, Noga AJ, Chang GJ. 2005. Comparative analysis of immunoglobulin M (IgM) capture enzymelinked immunosorbent assay using virus-like particles or virusinfected mouse brain antigens to detect IgM antibody in sera from patients with evident flaviviral infections. J Clin Microbiol, 43: 3227-3236.

Kang SM, Song JM, Quan FS, Compans RW. 2009. Influenza vaccines based on virus-like particles. Virus Res, 143: 140-146.

Khurana S, Wu J, Verma N, Verma S, Raghunandan R, Manischewitz J, King LR, Kpamegan E, Pincus S, Smith G, Glenn G, Golding H. 2011. H5N1 virus-like particle vaccine elicits crossreactive neutralizing antibodies that preferentially bind to the oligomeric form of influenza virus hemagglutinin in humans. J Virol, 85: 10945-10954.

Kong D, Wen Z, Su H, Ge J, Chen W, Wang X, Wu C, Yang C, Chen H, Bu Z. 2012. Newcastle disease virus-vectored Nipah encephalitis vaccines induce $\mathrm{B}$ and $\mathrm{T}$ cell responses in mice and long-lasting neutralizing antibodies in pigs. Virology, 432: 327-335.

L'Vov D K, Al'khovskii SV, Shchelkanov M, Shchetinin AM, Deriabin PG, Aristova VA, Gitel'man AK, Samokhvalov EI, Botikov AG. 2014. Taxonomic status of the Tyulek virus (TLKV) (Orthomyxoviridae, Quaranjavirus, Quaranfil group) isolated from the ticks Argas vulgaris Filippova, 1961 (Argasidae) from the birds burrow nest biotopes in the Kyrgyzstan. Vopr Virusol, 59: 28-32. (In Russian)

López-Macías C, Ferat-Osorio E, Tenorio-Calvo A, Isibasi A, Talavera J, Arteaga-Ruiz O, Arriaga-Pizano L, Hickman SP, Allende M, Lenhard K, Pincus S, Connolly K, Raghunandan R, 
Smith G, Glenn G. 2011. Safety and immunogenicity of a viruslike particle pandemic influenza A (H1N1) 2009 vaccine in a blinded, randomized, placebo-controlled trial of adults in Mexico. Vaccine, 29: 7826-7834.

Landry N, Ward BJ, Trépanier S, Montomoli E, Dargis M, Lapini G, Vézina L-P. 2010. Preclinical and Clinical Development of Plant-Made Virus-Like Particle Vaccine against Avian H5N1 Influenza. PLoS One, 5: e15559.

Li C, Liu F, Liang M, Zhang Q, Wang X, Wang T, Li J, Li D. 2010. Hantavirus-like particles generated in $\mathrm{CHO}$ cells induce specific immune responses in C57BL/6 mice. Vaccine, 28: 4294-4300.

Lindesmith LC, Ferris MT, Mullan CW, Ferreira J, Debbink K, Swanstrom J, Richardson C, Goodwin RR, Baehner F, Mendelman PM, Bargatze RF, Baric RS. 2015. Broad Blockade Antibody Responses in Human Volunteers after Immunization with a Multivalent Norovirus VLP Candidate Vaccine: Immunological Analyses from a Phase I Clinical Trial. PLoS Med, 12: 32.

Liu Y, Zhou J, Yu Z, Fang D, Fu C, Zhu X, He Z, Yan H, Jiang L. 2014. Tetravalent recombinant dengue virus-like particles as potential vaccine candidates: immunological properties. BMC Microbiol, 14: 233.

Lu B, Huang Y, Huang L, Li B, Zheng Z, Chen Z, Chen J, Hu Q, Wang H. 2010. Effect of mucosal and systemic immunization with virus-like particles of severe acute respiratory syndrome coronavirus in mice. Immunology, 130: 254-261.

Mandell RB, Koukuntla R, Mogler LJ, Carzoli AK, Freiberg AN, Holbrook MR, Martin BK, Staplin WR, Vahanian NN, Link CJ, Flick R. 2010. A replication-incompetent Rift Valley fever vaccine: chimeric virus-like particles protect mice and rats against lethal challenge. Virology, 397: 187-198.

Mani S, Tripathi L, Raut R, Tyagi P, Arora U, Barman T, Sood R, Galav A, Wahala W, de Silva A, Swaminathan S, Khanna N. 2013. Pichia pastoris-expressed dengue 2 envelope forms viruslike particles without pre-membrane protein and induces high titer neutralizing antibodies. PLoS One, 8: e64595.

McGinnes LW, Gravel KA, Finberg RW, Kurt-Jones EA, Massare MJ, Smith G, Schmidt MR, Morrison TG. 2011. Assembly and immunological properties of Newcastle disease virus-like particles containing the respiratory syncytial virus $F$ and $G$ proteins. J Virol, 85: 366-377.

Metz SW, Gardner J, Geertsema C, Le TT, Goh L, Vlak JM, Suhrbier A, Pijlman GP. 2013. Effective chikungunya virus-like particle vaccine produced in insect cells. PLoS Negl Trop Dis, 7: e2124.

Moore MD, Goulter RM, Jaykus LA. 2015. Human norovirus as a foodborne pathogen: challenges and developments. Annu Rev Food Sci Technol, 6: 411-433.

Mortola E, Roy P. 2004. Efficient assembly and release of SARS coronavirus-like particles by a heterologous expression system. FEBS Lett, 576: 174-178.

Noranate N, Takeda N, Chetanachan P, Sittisaman P, A AN, Anantapreecha S. 2014. Characterization of chikungunya viruslike particles. PLoS One, 9: e108169.

Oldstone MBA. 2002. Arenaviruses I -The epidemiology, molecular and cell biology of arenaviruses -Preface. Arenaviruses I, 262: V-Xii.

Overby AK, Popov V, Neve EP, Pettersson RF. 2006. Generation and analysis of infectious virus-like particles of uukuniemi virus (bunyaviridae): a useful system for studying bunyaviral packaging and budding. J Virol, 80: 10428-10435.

Patel MM, Hall AJ, Vinje J, Parashara UD. 2009. Noroviruses: A comprehensive review. J Clin Virol, 44: 1-8.

Purdy DE, Chang GJ. 2005. Secretion of noninfectious dengue viruslike particles and identification of amino acids in the stem region involved in intracellular retention of envelope protein. Virology, 333: 239-250.

Quan FS, Huang C, Compans RW, Kang SM. 2007. Virus-like particle vaccine induces protective immunity against homologous and heterologous strains of influenza virus. J Virol, 81: 3514-3524.

Quan FS, Kim Y, Lee S, Yi H, Kang SM, Bozja J, Moore ML, Compans RW. 2011. Viruslike particle vaccine induces protection against respiratory syncytial virus infection in mice. J Infect Dis, 204: 987-995.

Ramani S, Atmar RL, Estes MK. 2014. Epidemiology of human noroviruses and updates on vaccine development. Curr Opin Gastroenterol, 30: 25-33.

Rodriguez-Limas WA, Sekar K, Tyo KE. 2013. Virus-like particles: the future of microbial factories and cell-free systems as platforms for vaccine development. Curr Opin Biotechnol, 24: 1089-1093.

Roldão A, Mellado MCM, Castilho LR, Carrondo MJT, Alves PM. 2010. Virus-like particles in vaccine development. Expert Rev Vaccines, 9: 1149-1176.

Schmeisser F, Adamo JE, Blumberg B, Friedman R, Muller J, Soto J, Weir JP. 2012. Production and characterization of mammalian virus-like particles from modified vaccinia virus Ankara vectors expressing influenza H5N1 hemagglutinin and neuraminidase. Vaccine, 30: 3413-3422.

Schweitzer BK, Chapman NM, Iwen PC. 2009. Overview of the Flaviviridae With an Emphasis on the Japanese Encephalitis Group Viruses. Lab Medicine, 40: 493-499.

Scotti N, Rybicki EP. 2013. Virus-like particles produced in plants as potential vaccines. Expert Rev Vaccines, 12: 211-224.

Singh G, Kumar A, Singh K, Kaur J. 2015. Ebola virus: an introduction and its pathology. Rev Med Virol. doi: 10.1002/rmv. 1863.

Staples JE, Breiman RF, Powers AM. 2009. Chikungunya fever: an epidemiological review of a re-emerging infectious disease. Clin Infect Dis, 49: 942-948.

Strecker T, Eichler R, Meulen Jt, Weissenhorn W, Dieter Klenk H, Garten W, Lenz O. 2003. Lassa virus Z protein is a matrix protein sufficient for the release of virus-like particles. J Virol, 77: 10700-10705.

Swayne DE, Suarez DL. 2000. Highly pathogenic avian influenza. Rev Sci Tech, 19: 463-482.

Swenson DL, Warfield KL, Kuehl K, Larsen T, Hevey MC, Schmaljohn A, Bavari S, Aman MJ. 2004. Generation of Marburg virus-like particles by co-expression of glycoprotein and matrix protein. FEMS Immunol Med Microbiol, 40: 27-31.

Wagner R, Deml L, Schirmbeck R, Reimann J, Wolf H. 1994. Induction of a MHC class I-restricted, CD8 positive cytolytic T-cell response by chimeric HIV-1 virus-like particles in vivo: implications on HIV vaccine development. Behring Inst Mitt, 95: 23-34.

Walpita P, Barr J, Sherman M, Basler CF, Wang L. 2011. Vaccine Potential of Nipah Virus-Like Particles. PLoS One, 6: e18437.

Warfield KL, Aman MJ. 2011. Advances in virus-like particle vaccines for filoviruses. J Infect Dis, 204 Suppl 3: S1053-S1059.

Warfield KL, Bosio CM, Welcher BC, Deal EM, Mohamadzadeh M, Schmaljohn A, Aman MJ, Bavari S. 2003. Ebola virus-like particles protect from lethal Ebola virus infection. Proc Natl Acad Sci U S A, 100: 15889-15894.

Warfield KL, Posten NA, Swenson DL, Olinger GG, Esposito D, Gillette WK, Hopkins RF, Costantino J, Panchal RG, Hartley JL, Aman MJ, Bavari S. 2007. Filovirus-like particles produced in insect cells: immunogenicity and protection in rodents. J Infect Dis, 196 Suppl 2: S421-S429. 
WHO 2015. Ebola Situation Report 21 Oct 2015. http://apps. who. int/iris/bitstream/10665/190067/1/ebolasitrep_21Oct2015_eng.pdf

WHO 2016. Middle East respiratory syndrome coronavirus (MERSCoV) - Saudi Arabia. 22 June 2016. http://www.who.int/csr/don/ 22-june-2016-mers-saudi-arabia/en/

Yamaji H, Nakamura M, Kuwahara M, Takahashi Y, Katsuda T, Konishi E. 2013. Efficient production of Japanese encephalitis virus-like particles by recombinant lepidopteran insect cells. Appl Microbiol Biotechnol, 97: 1071-1079.

Yang L, Song Y, Li X, Huang X, Liu J, Ding H, Zhu P, Zhou P. 2012. HIV-1 virus-like particles produced by stably transfected Drosophila S2 cells: a desirable vaccine component. J Virol, 86: 7662-7676.
Zeltins A. 2013. Construction and characterization of virus-like particles: a review. Mol Biotechnol, 53: 92-107.

Zhang S, Liang M, Gu W, Li C, Miao F, Wang X, Jin C, Zhang L, Zhang F, Zhang Q, Jiang L, Li M, Li D. 2011. Vaccination with dengue virus-like particles induces humoral and cellular immune responses in mice. Virol J, 8: 333.

Zhao Q, Li S, Yu H, Xia N, Modis Y. 2013. Virus-like particlebased human vaccines: quality assessment based on structural and functional properties. Trends Biotechnol, 31: 654-663.

Zhou ZR, Wang ML, Deng F, Li TX, Hu ZH, Wang HL. 2011. Production of CCHF virus-like particle by a baculovirus-insect cell expression system. Virol Sin, 26: 338-346. 